\title{
A TV de Silvio Santos - estratégias mercadológicas na grade de programação do SBT: um enfoque quantitativo
}

\section{The TV owned by Silvio Santos - marketing strategies in the production the SBT schedule: a quantitative approach}

\author{
Cláudia Pereira Galhardi \\ Doutora em Comunicação Audiovisual, Revolución Tecnologica y Cambio Cultural pelo Departamento de Sociologia e \\ Comunicação da Universidade de Salamanca (USAL). Pós- doutorado na Fundação Oswaldo Cruz: Escola Nacional de Saúde \\ Pública Sergio Arouca (ENSP) - FIOCRUZ-RJ. \\ <claudiagalhardi@usal.es>
}

\section{Félix Ortega}

Doutor em Comunicação Audiovisual, Cultura e educação (Universidad de Salamanca, 2006). Professor da Facultad de Ciencias Sociales de la Universidad de Salamanca- USAL. Secretário General del Instituto Universitario de Investigación en Ciencias de la Educación de la Universidad de Salamanca.

$<$ fortegam@gmail.com>

\section{Juan José Igartua}

Doutor em Psicologia (Universidad del País Vasco, 1996) e Catedrático de Universidad del área de Comunicación Audiovisual y Publicidad da Universidad de Salamanca (Dpto. de Sociología y Comunicación).

<fiigartua@usal.es>

\section{RESUMO}

No Brasil, os concessionários de TV, teoricamente, mantêm um compromisso com o Governo Federal para que operem o espectro eletromagnético como um bem público, com ênfase em princípios educativos, artísticos, culturais e informativos. Em face destas constatações, o presente artigo visa a revelar o atual cenário de oferta de programas da emissora SBT em São Paulo, no estado do Rio Grande do Sul e na TV Aratu, afiliada do SBT na Bahia. Para tanto, realizouse uma investigação empírica quantitativa a partir da análise de conteúdo da programação exibida durante o ano de 2012. Os resultados demonstram uma programação marcada por uma ideologia empresarial, o não cumprimento do marco legal vigente, nula produção de conteúdos educativos e culturais e massiva oferta de importação estrangeira.

Palavras-chave:: Sistema Brasileiro de Televisão. Análise de Conteúdo. Método quantitativo.

\begin{abstract}
In Brazil, the TV stations, theoretically, maintain a commitment to the Federal Government in order to operate the electromagnetic spectrum as a public good, focusing on educational, artistic, cultural and informative principles. According to these findings, the present article aims to reveal the current scenario of supply of SBT station's programs in Sao Paulo, in the state of Rio Grande do Sul and the Aratu TV, SBT's affiliate station in Bahia. Therefore, a quantitative empirical research was carried out from the programming content analysis broadcasted during the year 2012. The results show a schedule marked by a corporate ideology, failure to comply with the current legal law, null production of educational and cultural contents, and massive supply of foreign imports.
\end{abstract}

Keywords: Sistema Brasileiro de Televisão. Content Analysis. Quantitative Method. 


\section{Introdução}

Escrever sobre o Sistema Brasileiro de Televisão (SBT) não foi uma tarefa fácil. Apesar de ser a segunda maior emissora do país, e considerando seus 34 anos de existência, é lamentável observar que, ao realizar um levantamento exaustivo de literatura, não há produção intelectual suficiente para que se possa descrever sua história e desenvolvimento. Em um contexto literário sobre a indústria da TV no Brasil, as produções científicas iniciaram nos anos de 1960, sobre a ótica da cultura, comunicação de massa e indústria cultural, apoiadas em pontos de vistas teóricos como o informacional, o funcionalista, o estruturalista e a teoria crítica (Sacramento, 2013). Evidenciaram-se, também, pesquisas apoiadas em fatores e acontecimentos da evolução histórica da TV, veja-se, por exemplo, Reimão (2000), Wolton (1996), Bolaño (1999) e Caparelli (1982).

Agrega-se a esse agravante, uma literatura emergente em análise de conteúdo das produções e consumos audiovisuais, concomitantemente a uma ausente observação acadêmica crítica mais consistente nas produções televisivas, assim como a existente tradição crítica cinematográfica (Lozano, 2004; Ortiz, 2006).

A partir dessa constatação, muitas foram as inquietudes que nos conduziram a tencionar essa pesquisa. A priori devemos mencionar que o estudo da televisão brasileira não deve se deter somente em conceitos teóricos, mas também ter em conta a prerrogativa dos conteúdos produzidos e ofertados, como fator dominante no desenvolvimento de valores nacionais, na função educativa, programação regional, na difusão e pluralismo de conteúdos culturais regionais na sociedade contemporânea brasileira (Casetti e Di Chio, 1999; Fechine, 2008).

Tendo em conta esses indicativos, em termos jurídicos governamentais, - Artigo 221, Inciso IV, da Constituição da República Federativa do Brasil de 1988, que regulamenta a programação das emissoras de televisão, tem como base os seguintes princípios: I - preferência às finalidades educativas, artísticas, culturais e informativas; II - promoção da cultura nacional e regional e estímulo à produção independente que objetive sua divulgação; III - regionalização da produção cultural, artística e jornalística, conforme porcentuais estabelecidos na lei; IV - respeito aos valores éticos e sociais da pessoa e da família.

Um meio de comunicação de massa de importantes dimensões econômicas, políticas e culturais, caracterizado por sua diferenciada função central de veículo público, a indústria da TV é considerada o espelho da identidade e unificação nacional, que de uma forma homogênea e sincrônica 
alcança comunicar-se com todas as esferas da sociedade contemporânea (Jambeiro, Brittos, Simis, 2007; Figueira, 2013; Wolton, 2013).

Em face ao mencionado anteriormente, o estudo em questão anuncia claramente por meio da análise quantitativa da oferta de programação de cabeça da Rede SBT e suas afiliadas, o não cumprimento do marco legal vigente, nula produção de conteúdos educativos e exagerada produção de programas de entretenimento e programas de importação estrangeira.

\section{A TV de Silvio Santos: uma aproximação teórica}

Para que iniciemos a história do SBT faz-se necessário mencionar o trabalho da pesquisadora Maria Celeste Mira (1995): "Circo eletrônico: Silvio Santos e o SBT". Desde uma perspectiva culturalista, a autora retrata a trajetória do proprietário da segunda maior emissora em audiência do país. "Da vida de camelô ao primeiro canal de TV" é o título que dá inicio ao primeiro capítulo de sua obra.

Senhor Abravanel, conhecido no Brasil pelo seu nome artístico Silvio Santos, iniciou suas atividades como apresentador de programas de auditório, comprando horários aos domingos na grade da programação da TV Paulista, em 1962. Utilizando somente a infraestrutura e parte técnica e operacional da emissora contratada, Silvio Santos desenvolveu seu próprio estilo de fazer televisão, sinalizando para um perfil de produção de programas batizados como "popularesco". Produziu e apresentou os programas "Vamos brincar de Forca" e "Pra ganhar é só rodar", esse último dedicado aos compradores do "Baú da Felicidade", produto comercializado por umas das empresas que faria parte dentro de alguns anos, do Grupo Silvio Santos. Em 1968, o animador tinha, inicialmente, três empresas, além do Baú da Felicidade, a segunda dedicada ao ramo de construtora e a terceira conhecida como a Publicidade Silvio Santos, essa terceira "embrião do Sistema Brasileiro de Televisão, criada em 1962, em função do volume de negócios do Programa Silvio Santos" [...] (Mira, 1995, p.18). Em 1975, o Grupo S.S estava formado por 20 empresas nos mais diversos segmentos, pontua a autora.

Conhecido animador de programas de auditório, desde o ano de 1971, lutava por conseguir sua própria emissora que, por inúmeras vezes, teve seus pedidos de concessão de um canal de televisão negado. De apresentador de TV independente, Silvio Santos torna-se proprietário de um canal de TV, concedido pelo então presidente Ernesto Geisel, por meio do decreto n 76.488, no dia 22 de outubro de 1975, na cidade do Rio de Janeiro. Nomeada como TVS, inicia suas transmissões de programas em maio de 1976, ganhando popularidade e 
conquistando espaço no mercado da TV. Em 1981, nasce o Sistema Brasileiro de Televisão, canal 4, na cidade de São Paulo (Santos, 2000; Brittos, 2004; Bolaño, 2004; Biondi, Charão, 2008).

Com um público cativo conquistado nas emissoras em que atuou somente como apresentador, o dono do SBT beneficia-se dos seguidores de seus programas e alcança em curto tempo o segundo lugar no ranking de audiência das emissoras abertas no país, em guerra com a então líder Rede Globo de Televisão (Brittos, 2002; Bolaño, 2004).

Animador de programas de TV e vendedor são as duas atividades que norteiam a vida profissional de Silvio Santos (Mira, 1995), bem representadas na grade da programação do SBT, como demonstraremos com as contribuições literárias e os dados quantitativos que serão apresentados por nossa pesquisa a seguir.

\section{A programação do Silvio Santos}

Partindo da premissa de que os critérios de ações e decisões tomadas por uma emissora atuam de forma relacional, possibilitando, dessa maneira, reconhecer o perfil e a política de sua programação (Rondelli, 1998; Duarte, 2003), aqui esboçaremos o estilo de "fazer TV" de Silvio Santos.

No princípio de suas atividades, o canal TVS não competia com o mercado publicitário. Silvio Santos seguiu com sua fórmula popular de produzir programas de auditório de baixo custo e de forte apelação ao grotesco. Esse formato de programas não angariava grandes anunciantes, mas servia-lhe para difundir e consolidar seus negócios empresariais. Em 1977, foi promulgada a nova lei que exigia que as emissoras transmitissem programas durante 18 horas diariamente. Nesse período, o SBT realizava transmissões das $18 \mathrm{~h}$ às $24 \mathrm{~h}$. Para que a emissora cumprisse com a lei estabelecida, passaram a importar, em princípio, programas de produção americana como os filmes, séries, desenhos animados, musicais, dentre outros (Bolaño, 2004).

Nos anos de 1980 e 1990, a linha de programação do SBT seguiu ofertando conteúdos populares, "cujas pautas exploram o ridículo, o grotesco, aquilo classificado pela crítica jornalística como de mau gosto" (Rondelli, 1998, p. 2).

Nesse cenário, encabeçam nos anos 90 programas como o polêmico "Aqui Agora", classificado pela emissora como jornalístico, "Márcia", "Ratinho Livre", "Madalena", denominados reality shows, com marcada apelação ao drama, apresentadores que exploram problemas de pessoas humildes, denominados 
como a "caridade eletrônica" e quadros que atuavam como tribunais de pequenas causas (Rondelli, 1998).

Associa-se a esse panorama, também, os programas de auditório, questão abordada pela pesquisa intitulada: "Silvio Santos vem aí - programas de auditório do SBT numa perspectiva semiótica", tese doutoral desenvolvida por Silvia Maria de Sousa, em 2009.

Apoiada na semiótica do discurso, Souza (2009) realiza uma análise de quatro programas de auditório da emissora, classificando o corpus desse estudo da seguinte forma: "Gente que brilha", subgênero show de variedades; "Roda a Roda", subgênero game show; "Rei Majestade", subgênero show de variedades e "Topa ou não Topa", subgênero game show. A revelação trazida pela autora é de um apresentador de programas centrado em difundir as empresas do Grupo Sílvio Santos, disseminadas nos programas de game show e auditórios. "Em função de o SBT ser um canal que veicula largamente seus próprios produtos, como: carnê do Baú, computador do milhão, o relógio do Silvio Santos, etc. [...], a emissora realiza o merchandising internamente, sendo seu próprio patrocinador de programas.

Nesse contexto, outra peculiaridade na forma com que Silvio Santos administra sua emissora é revelada por meio de uma programação "marcada por uma instabilidade, idas e vindas, mudanças de horário, repetições de programas, suspensão de outros"(Souza, 2009, p.182). Essa constatação explicita uma subjetividade na forma com que o empresário dirige a emissora.

Nesse mesmo âmbito, há algumas contribuições informativas dos apresentadores de programas e artistas que trabalham para o SBT. Segundo eles, a grade televisiva é uma verdadeira "caixa de surpresas", os artistas da emissora nunca sabem ao certo suas atrações que serão transmitidas no dia e na hora estabelecida, pois o empresário comanda as atrações seguindo a audiência. Perseguindo resultados em curto prazo e principalmente os números do Ibope, a programação vai de encontro, exclusivamente, a números. Neste contexto, o apresentador, sempre em busca de maior audiência, ao adquirir um pacote de programas infantis, decidiu veiculá-los no horário das $19 \mathrm{~h}$ (que pertencia a um telejornal), almejando o público infanto-juvenil que chega nesse horário da escola e ligam a TV (Veja, 2000). Por sua vez, as alterações realizadas na grade televisiva do SBT foram evidenciadas por nossa pesquisa de 2009, intitulada: "Fluxo da programação televisiva aberta no Brasil: uma nova proposta metodológica e caso prático no Estado de São Paulo". Tal constatação foi legitimada ao estabelecer a definição terminológica ao objeto de estudo. Apoiamo-nos nas produções científicas do gênero da televisão brasileira e 
assistindo diretamente aos programas que seriam transmitidos, segundo as informações publicadas no jornal Folha de São Paulo e na própria página da web da emissora, para comprovar o conteúdo do programa com gênero anunciado, evidenciamos que, alguns programas tinham sido substituídos por outras atrações. Outro fator observado foram alguns formatos como, por exemplo, os classificados como jornalísticos pela emissora. O trabalho de leitura textual comprovou que o programa continha várias outras atrações incorporadas no mesmo formato que o descaracterizava como programa jornalístico, assim como diferentes conteúdos analisados. Cabe precisar que essa observação é apenas complementar e de apoio às informações mencionadas anteriormente, uma vez que nossa pesquisa teve como foco um trabalho de análise quantitativa.

Observou-se que a prática do merchandising é imperativa no SBT. Ocupando a segunda posição dentre as cinco emissoras comerciais abertas no Brasil, o SBT situa-se como líder no ranking do merchandising de caráter testemunhal (32\%) e merchandising de ação integrada (37\%) (Grupo de mídia, 2013).

Outro viés de análise que reforça o perfil da grade de programação ofertada pelo SBT é a entrevista realizada com Silvio Santos e concedida à Revista Veja (2000). Sobre o público que assiste à sua programação, delineia o seguinte parecer:

O brasileiro é um povo humilde. A televisão é a sua única diversão. Esse povo não quer ligar a televisão para ter aula ou ter cultura. (...) Temos de dar ao povo o que o povo quer. Se for samba, será samba. "Se for mulher com pouca roupa, será mulher com pouca roupa" (Veja, 2000).

\section{Método da investigação}

Na metodologia orientada aos estudos dos fenômenos reais e de finalidade preditiva, a análise de conteúdo possui características fundamentalmente empíricas e exploratórias, é aplicada a todas as formas de comunicação e setores das ciências humanas por meio de seu código linguístico, aportando um enunciado quantitativo mais convincente aos estudos dos fenômenos simbólicos e simultaneamente buscando seu papel social, seus efeitos e significados, avaliando criticamente os achados existentes diretamente e estabelecendo, sem dúvida, o objetivo da pesquisa (Krippendorff, 1990, 2013; Bardin, 2011).

O procedimento aplicado a todas as formas de comunicação, independentemente de sua natureza, o método de análise de conteúdo de mensagens priorizam o código linguístico que, na prática, pode não se 
dissociar, apresentando-se em duas funções: a primeira como uma função heurística, enriquecendo a finalidade exploratória, aumentando a propensão ao descobrimento, e a segunda é o papel de administrador da avaliação. Hipótese levantada sobre forma de questionamento ou afirmação efêmera recorreu para o método de análise ordenado (Bardin, 1977). Para tanto, a seguir apresentamse as fases de trabalho constituídas no desenvolvimento deste estudo.

Assim, na presente pesquisa, realiza-se uma análise quantitativa da emissora cabeça de rede Sistema Brasileira de Televisão no Estado de São Paulo, com uma amostra de 2018 programas examinados; Sistema Brasileiro de Televisão no estado do Rio Grande do Sul, com uma amostra de 2144 programas analisados e a afiliada TV Aratu, com 2889 programas examinados no estado da Bahia. O período estabelecido para o exame da programação televisiva compreendeu um total de 12 meses consecutivos, iniciados em 16 de janeiro até 31 de dezembro de 2012. A seleção da amostra representativa definiu-se a partir da Seleção da amostra Ortega Galhardi (SMOG). Iniciou-se a coleta de dados a partir da primeira semana do mês em curso de cada semana em análise e segue os demais dias em sentido diagonal, incluindo os fins de semana completos. Analisou-se a transmissão da programação no decorrer das 24 horas de exibição, com horário inicial às 06h00min e finalizando às 05h59min do dia seguinte. A fonte de informação utilizada é o jornal "O Estado de São Paulo".

- Tabela 1. Distribuição dos períodos de transmissão

\begin{tabular}{|ll|}
\hline Período & $\begin{array}{l}\text { Horário de transmissão } \\
\text { do programa }\end{array}$ \\
\hline A & $06: 00$ até $09: 59$ \\
\hline AA & $10: 00$ até $14: 59$ \\
\hline AAA & $15: 00$ até $18: 59$ \\
\hline AAAA & $19: 00$ até $23: 59$ \\
\hline AAAAA & $00: 00$ até $05: 59$ \\
\hline
\end{tabular}

Fonte: Adaptado de (Lozano; Garza, 2005).

Por se tratar de um trabalho de análise de conteúdo, como em qualquer área de estudo de natureza empírica, o processo de definição conceitual e 
operacionalização das categorias está entre os passos mais importantes do processo de investigação (Igartua, 2006; Bardin, 2011). Portanto, foi significativo adotar a definição terminológica precisa das unidades da comunicação discursiva ao analisar e, nesse sentido, realizamos uma exploração qualitativa dos conceitos aplicados às pesquisas de análise de conteúdos com diferentes perspectivas teóricas apresentadas até o momento, quais sejam: Filho (2009); Bakhtin (2006); Nordenstreng y Varis (1976); Souza (2004); Malcher (2001); (ANDI) (2006); Mazziotti e outros (2001); Garza (2005); Melo (1985); Tondato (2004); Reimão (2000).

No quadro abaixo, apresentamos a construção conceitual das categorias e variáveis aplicadas a este estudo, com algumas adequações, para melhor desenvolvimento da pesquisa.

\section{Tabela 2. Classificação indicativa}

\begin{tabular}{|c|l}
\hline \multicolumn{1}{|c|}{ Macrogênero } & \multicolumn{1}{|c}{ Gênero } \\
\hline \multicolumn{1}{|c|}{ Informação } & \begin{tabular}{|l|l}
\hline Telejornal \\
Reportagem \\
Entrevista \\
Documentário \\
Revista Eletrônica
\end{tabular} \\
\hline \begin{tabular}{l} 
Auditório \\
Desenho Animado \\
Culinário \\
Novela \\
Séries \\
Seriado \\
Filmes \\
Esportivo \\
\hline Programa Esportivo \\
Musical \\
Talk Show \\
Reality Show \\
Infantil \\
Humoristico \\
Variedades \\
Games Show \\
Quiz Show \\
Eventos
\end{tabular} \\
\hline Religioso
\end{tabular}

Fonte: Os autores.

\section{Checagem da confiabilidade da codificação}

Outro aspecto, ainda sobre o processo de investigação, é contrastar a qualidade dos dados de um estudo de análise de conteúdo, sendo necessário que esses dados sejam processados por uma avaliação de confiabilidade da 
decodificação. Nesse sentido, é imprescindível a aplicação do coeficiente de Kappa de Cohen que possibilita que distintos codificadores avaliem um mesmo material e obtenham, em grande maioria, um grau majoritário de concordância de cada variável que compõe o livro de códigos. Para este estudo, os avaliadores envolvidos no processo de codificação selecionaram como amostra a contrastar $10 \%$ das respectivas unidades de análise, sendo sorteadas de um total de 7051 programas codificados. Fazemos notar que, o grau de acordo entre os colaboradores aproximou-se a 1.0, correspondendo a uma concordância perfeita segundo os indicadores da tabela que ilustramos a seguir.

\section{- Figura 1. Indicadores dos níveis de concordância entre intercodificadores}

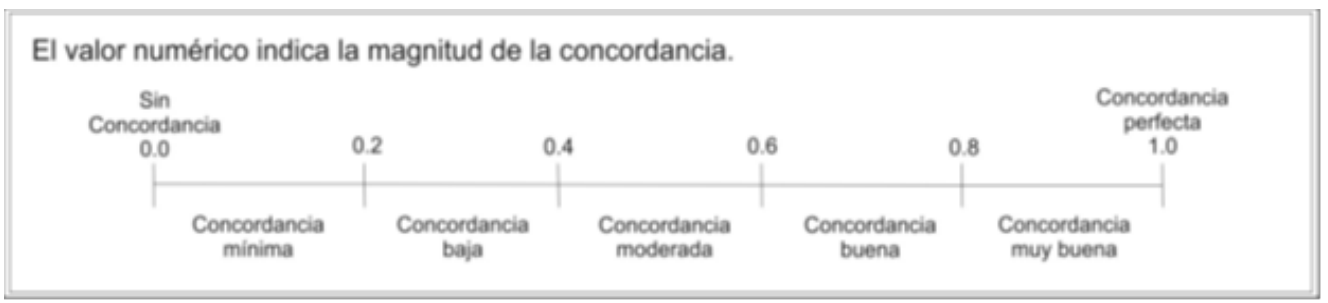

Fonte: Sociedade Peruana de Bioestatística(2010).

\section{Desenho metodológico}

No quadro a seguir, pode-se visualizar o desenvolvimento metódico constituído de uma sequência de oito passos.

\section{- Tabela 3. Passos da análise de conteúdo}

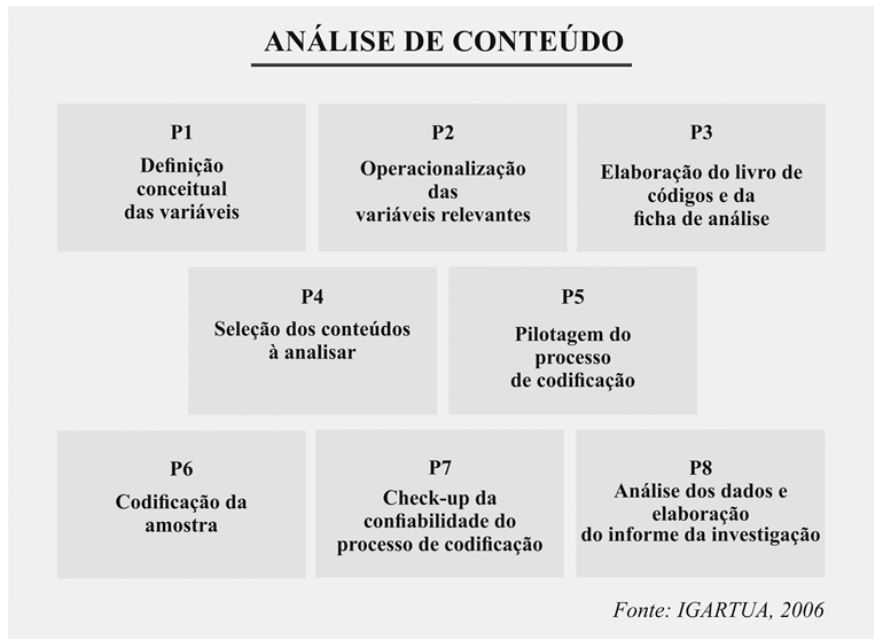

Fonte: Adaptação de (Igartua, 2006). 
Na aplicação da análise de conteúdo, o recurso que viabiliza executar toda a operação e formulação de hipóteses é a análise estatística dos dados. Neste estudo, utilizamos o SPSS Statistical Package for the Social Sciences.

A seguir, apresentamos os dados das tabelas, com os resultados estatísticos desta investigação.

Tabela 4. Distribuição da categoria macro gênero das emissoras SBT-SP-RGS e TV Aratu

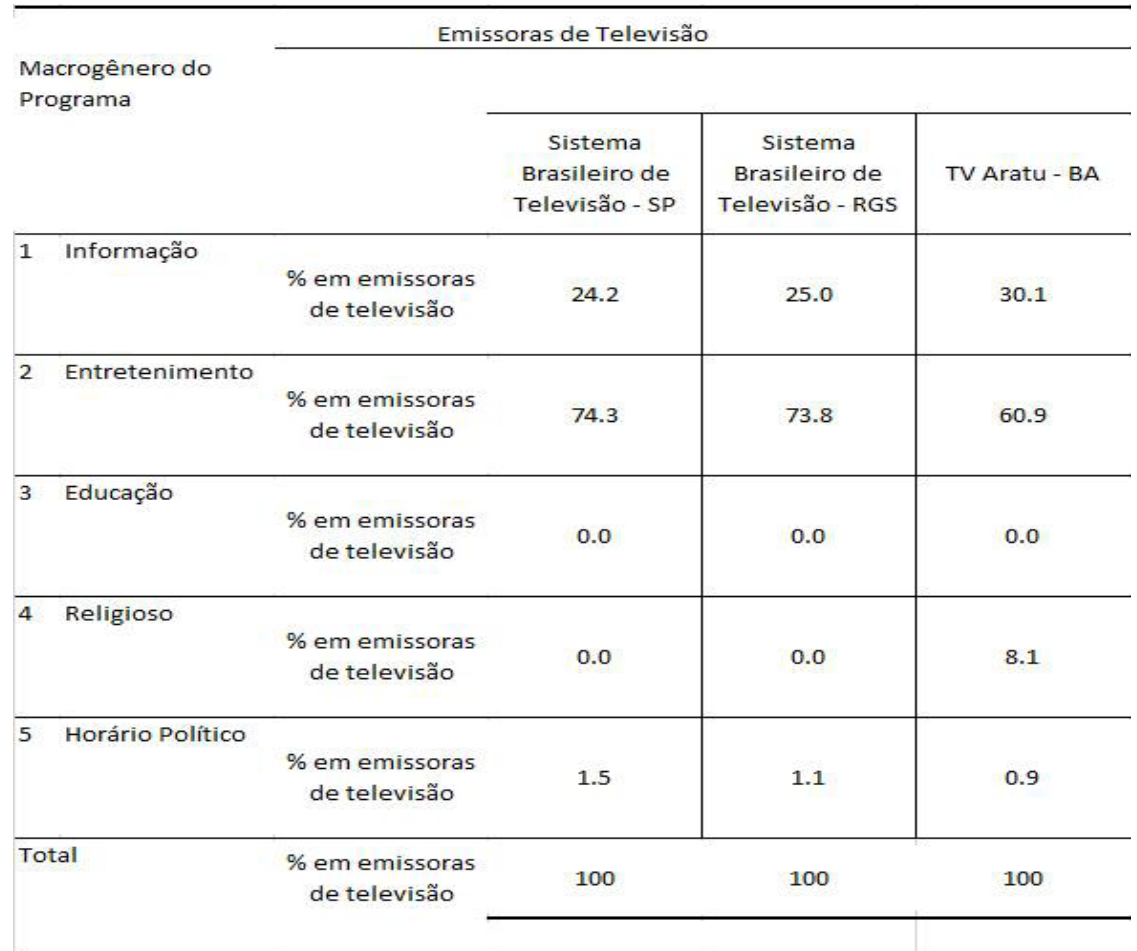

Fonte: Os autores.

Observa-se que o SBT-SP produziu $24,2 \%$ de conteúdos informativos, $74,3 \%$ de programas de entretenimento e 1,5\% de transmissão de programas políticos. Segundo classificação estabelecida, verifica-se como nula a produção de conteúdos educativos e religiosos no referido Estado.

Já no Rio Grande do Sul, o Sistema Brasileiro de Televisão produziu 25\% de programas informativos, $73,8 \%$ de conteúdos de entretenimento e $1,1 \%$ de exibição de horário político, também neste Estado houve ausência de programas educativos e religiosos.

Nota-se na afiliada TV Aratu um acréscimo nos programas informativos $(30,1 \%)$, uma redução nos conteúdos de entretenimento $(60,9 \%)$, inexistência 
de produção de programas educativos, transmissão de programas religiosos $(8,1 \%)$ e $0,9 \%$ de emissão de programas políticos.

Tabela 5. Gênero por nacionalidade de transmissão Sistema Brasileiro de Televisão no estado de São Paulo

\begin{tabular}{l|c|c|c|c|c}
\hline \multicolumn{1}{|c|}{ Gênero } & $\begin{array}{c}\text { Programa } \\
\text { produção } \\
\text { nacional }\end{array}$ & $\begin{array}{c}\text { Programa } \\
\text { produção } \\
\text { regional }\end{array}$ & $\begin{array}{c}\text { Programa } \\
\text { importação } \\
\text { Estados Unidos }\end{array}$ & $\begin{array}{c}\text { Programa } \\
\text { importação } \\
\text { México }\end{array}$ & Total \\
\hline Telejornal & 26.7 & 0.0 & 0.0 & 0.0 & 15.7 \\
\hline Reportagem & 10.6 & 0.0 & 0.0 & 0.0 & 5.9 \\
\hline Entrevista & 1.9 & 0.0 & 0.0 & 0.0 & 1.0 \\
\hline Documentário & 3.8 & 0.0 & 0.0 & 0.0 & 2.1 \\
\hline Auditório & 8.5 & 0.0 & 0.0 & 0.0 & 4.8 \\
\hline Desenho & 0.0 & 0.0 & 7.6 & 0.0 & 2.8 \\
\hline Animado & 13.1 & 0.0 & 0.0 & 18.7 & 9.1 \\
\hline Novela & 0.0 & 0.0 & 52.9 & 81.3 & 25.0 \\
\hline Séries & 0.0 & 0.0 & 32.5 & 0.0 & 10.8 \\
\hline Seriado & 0.0 & 0.0 & 6.9 & 0.0 & 3.1 \\
\hline Filme & 1.1 & 0.0 & 0.0 & 0.0 & 0.6 \\
\hline Musical & 4.5 & 0.0 & 0.0 & 0.0 & 2.5 \\
\hline Talk Show & 8.6 & 0.0 & 0.0 & 0.0 & 4.8 \\
\hline Infantil & 2.7 & 0.0 & 0.0 & 0.0 & 1.5 \\
\hline Humorístico & 2.7 & 0.0 & 0.0 & 0.0 & 1.5 \\
\hline Propaganda & 11.4 & 0.0 & 0.0 & 0.0 & 6.4 \\
\hline Política & 4.2 & 0.0 & 0.0 & 0.0 & 2.4 \\
\hline Variedades & 100 & 100 & 100 & 100 \\
\hline Gatal & & & & & \\
\hline
\end{tabular}

Fonte: Os autores.

No estado de São Paulo, observou-se que os telejornais (26,6\%), reportagens $(10,6 \%)$, entrevistas (1,9\%), documentários $(3,8 \%)$, auditório $(8,5 \%)$, telenovela $(13,1 \%)$, musical $(1,1 \%)$, talk show $(4,5 \%)$, infantil $(8,6 \%)$, humorístico $(2,7 \%)$, propaganda $(2,7 \%)$, variedades $(11,4 \%)$, game show $(4,2 \%)$ são exclusivamente de produção nacional. Note-se nula a produção de programas regionais no referido Estado.

A exibição de conteúdos importados diretamente dos Estados Unidos está dividida nos seguintes gêneros: desenho animado (7,6\%) série $(52,9 \%)$, 
seriado (32,5\%), filme (6,9\%). Programas de importação do México são ofertados nos seguintes gêneros: telenovelas $(18,7 \%)$ e série $(81,3 \%)$.

Tabela 6. Gênero por nacionalidade de transmissão: Sistema Brasileiro de Televisão no estado do Rio Grande do Sul

\begin{tabular}{|c|c|c|c|c|c|}
\hline Gênero & $\begin{array}{c}\text { Programa } \\
\text { produção } \\
\text { nacional }\end{array}$ & $\begin{array}{c}\text { Programa } \\
\text { produção } \\
\text { regional }\end{array}$ & $\begin{array}{c}\text { Programa } \\
\text { importação } \\
\text { Estados Unidos }\end{array}$ & $\begin{array}{l}\text { Programa } \\
\text { importação } \\
\text { México }\end{array}$ & Total \\
\hline Telejornal & 26.7 & 79.0 & 0.0 & 0.0 & 17.1 \\
\hline Reportagem & 11.2 & 0.0 & 0.0 & 0.0 & 5.9 \\
\hline Entrevista & 2.1 & 0.0 & 0.0 & 0.0 & 1.1 \\
\hline Documentário & 3.4 & 0.0 & 0.0 & 0.0 & 1.8 \\
\hline Auditório & 8.6 & 0.0 & 0.0 & 0.0 & 4.5 \\
\hline $\begin{array}{l}\text { Desenho } \\
\text { Animado }\end{array}$ & 0.0 & 0.0 & 8.0 & 0.0 & 2.8 \\
\hline Novela & 13.0 & 0.0 & 0.0 & 19.7 & 8.6 \\
\hline Séries & 0.0 & 0.0 & 49.2 & 79.3 & 23.6 \\
\hline Seriado & 0.0 & 0.0 & 35.7 & 0.0 & 12.1 \\
\hline Filme & 0.0 & 0.0 & 7.2 & 0.0 & 3.2 \\
\hline Musical & 1.1 & 21.0 & 0.0 & 0.0 & 1.4 \\
\hline Talk Show & 4.6 & 0.0 & 0.0 & 0.0 & 2.4 \\
\hline Infantil & 8.5 & 0.0 & 0.0 & 0.0 & 4.5 \\
\hline Humorístico & 1.9 & 0.0 & 0.0 & 0.0 & 1.0 \\
\hline $\begin{array}{l}\text { Propaganda } \\
\text { Política }\end{array}$ & 2.2 & 0.0 & 0.0 & 0.0 & 1.5 \\
\hline Variedades & 12.5 & 0.0 & 0.0 & 0.0 & 6.6 \\
\hline Game Show & 4.1 & 2.2 & 0.0 & 0.0 & 6.6 \\
\hline Total & 100 & 100 & 100 & 100 & 100 \\
\hline
\end{tabular}

Fonte: Os autores.

No Estado do Rio Grande do Sul, apresentam-se os seguintes dados: telejornais $(26,7 \%)$, reportagens $(11,2 \%)$, entrevistas $(2,1 \%)$, documentário $(3,4 \%)$, auditório $(8,6 \%)$, telenovela $(13,0 \%)$, musical $(1,1 \%)$, talk show $(4,6 \%)$, infantil $(8,5 \%)$, humorístico $(1,9 \%)$, propaganda política $(2,2 \%)$, variedades $(12,5 \%)$, game show $(4,1 \%)$ são unicamente de produção nacional. Constata-se que dois gêneros são produzidos para transmissão regional, são os telejornais (79\%) e musical (21,0\%). A exibição de conteúdos importados diretamente dos Estados Unidos está dividida nos seguintes gêneros: desenho animado (8,0\%), 
série (49,2\%), seriado (35,7\%), filme (7,2\%). Programas de importação do México são ofertados nos seguintes gêneros: telenovelas (19,7\%) e série $(79,3 \%)$.

Tabela 7. Gênero por nacionalidade de transmissão TV Aratu no estado da Bahia

\begin{tabular}{l|c|c|c|c|c|}
\hline \multicolumn{1}{|c|}{ Gênero } & $\begin{array}{c}\text { Programa } \\
\text { produção } \\
\text { nacional }\end{array}$ & $\begin{array}{c}\text { Programa } \\
\text { produção } \\
\text { regional }\end{array}$ & $\begin{array}{c}\text { Programa } \\
\text { importação } \\
\text { Estados Unidos }\end{array}$ & $\begin{array}{c}\text { Programa } \\
\text { importação } \\
\text { México }\end{array}$ & Total \\
\hline Telejornal & 21.1 & 19.1 & 0.0 & 0.0 & 15.5 \\
\hline Reportagem & 14.5 & 19.9 & 0.0 & 0.0 & 12.9 \\
\hline Entrevista & 2.7 & 2.6 & 0.0 & 0.0 & 2.0 \\
\hline Documentário & 4.7 & 0.0 & 0.0 & 0.0 & 2.0 \\
\hline Auditório & 8.9 & 0.0 & 0.0 & 0.0 & 3.7 \\
\hline Desenho & 0.0 & 0.0 & 12.3 & 0.0 & 2.2 \\
Animado & 10.9 & 0.0 & 0.0 & 22.8 & 5.9 \\
\hline Novela & 0.0 & 0.0 & 44.6 & 77.2 & 12.2 \\
\hline Séries & 0.0 & 0.0 & 32.5 & 0.0 & 5.7 \\
\hline Seriado & 0.0 & 0.0 & 10.6 & 0.0 & 2.0 \\
\hline Filme & 0.0 & 4.6 & 0.0 & 0.0 & 1.6 \\
\hline Esportivo & 1.0 & 2.0 & 0.0 & 0.0 & 1.1 \\
\hline Musical & 4.5 & 3.5 & 0.0 & 0.0 & 3.1 \\
\hline Talk Show & 0.0 & 1.8 & 0.0 & 0.0 & 0.6 \\
\hline Reality Show & 9.1 & 3.4 & 0.0 & 0.0 & 5.0 \\
\hline Infantil & 1.7 & 0.0 & 0.0 & 0.0 & 0.7 \\
\hline Humorístico & 0.0 & 23.8 & 0.0 & 0.0 & 8.2 \\
\hline Culto Religioso & 2.1 & 0.0 & 0.0 & 0.0 & 0.9 \\
\hline Propaganda & 15.0 & 13.0 & 0.0 & 0.0 & 10.8 \\
\hline Política & 3.8 & 2.4 & 0.0 & 0.0 & 2.4 \\
\hline Variedades & 0.0 & 0.1 & 0.0 & 0.0 & 0.1 \\
\hline Game Show & 0.0 & 3.8 & 0.0 & 0.0 & 1.3 \\
\hline Quiz Show & 100 & 100 & 100 & 100 & 100 \\
\hline Telecompra & Total & & & & \\
\hline & & & & & \\
\hline
\end{tabular}

Fonte: Os autores.

No estado da Bahia, observou-se que os telejornais $(21,1 \%)$, reportagens $(14,5 \%)$, entrevistas $(2,7 \%)$, documentário $(4,7 \%)$, auditório $(8,9 \%)$, telenovela $(10,9 \%)$, musical (1,0\%), talk show $(4,5 \%)$, infantil $(9,1 \%)$, humorístico $(1,7 \%)$, propaganda política $(2,1 \%)$, variedades $(15,0 \%)$ e game show $(3,8 \%)$ são 
exclusivamente de produção nacional. Um elemento particularmente notável é a inversão de produção regional no estado da Bahia, sobretudo, o gênero culto religioso. Produziram-se os seguintes gêneros, a saber: telejornais (19,1\%), reportagens (19,9\%), entrevistas (2,6\%), esportivo (4,6\%), musical $(2,0 \%)$, talk show $(3,5 \%)$, infantil $(3,4 \%)$, culto religioso $(23,8 \%)$, variedades $(13,0 \%)$, game show (2,4\%), Quiz show (0,1\%), tele compra (3,8\%). A exibição de conteúdos importados diretamente dos Estados Unidos está dividida nos seguintes gêneros: desenho animado (13,3\%), série $(44,6 \%)$, seriado $(32,5 \%)$ e filme $(10,6 \%)$. Programas de importação do México são ofertados nos seguintes gêneros: telenovelas $(22,8 \%)$ e série $(72,2 \%)$.

Tabela 8. Gênero por período de transmissão do Sistema Brasileiro de Televisão no estado de São Paulo

\begin{tabular}{|c|c|c|c|c|c|c|c|}
\hline \multirow{2}{*}{\multicolumn{2}{|c|}{ Gênero }} & \multicolumn{5}{|c|}{ Período de Transmissão } & \multirow[t]{2}{*}{ Total } \\
\hline & & A & AA & AAA & AAAA & AAAAA & \\
\hline 1 & Telejornal & 20.8 & 0.0 & 2.7 & 19.7 & 26.1 & 15.7 \\
\hline 2 & Reportagem & 27.9 & 0.0 & 0.6 & 5.8 & 2.0 & 5.9 \\
\hline 3 & Entrevista & 0.0 & 0.0 & 0.0 & 0.0 & 3.5 & 1.0 \\
\hline 4 & Documentário & 8.1 & 0.0 & 4.4 & 0.0 & 0.8 & 2.1 \\
\hline 5 & Auditório & 0.0 & 6.9 & 14.7 & 5.0 & 0.0 & 4.8 \\
\hline 6 & Desenho Animado & 1.8 & 15.4 & 0.0 & 0.0 & 0.0 & 2.8 \\
\hline 7 & Novela & 0.0 & 13.6 & 32.7 & 5.8 & 0.0 & 9.1 \\
\hline 8 & Séries & 15.5 & 54.8 & 14.7 & 9.1 & 31.1 & 25.0 \\
\hline 9 & Seriado & 0.0 & 5.4 & 0.0 & 0.2 & 32.9 & 10.8 \\
\hline 10 & Filme & 0.0 & 0.0 & 0.0 & 9.5 & 3.2 & 3.1 \\
\hline 11 & Musical & 0.0 & 0.0 & 0.0 & 2.6 & 0.0 & 0.6 \\
\hline 12 & Talk Show & 0.0 & 0.0 & 15.0 & 0.0 & 0.0 & 2.5 \\
\hline 13 & Infantil & 25.8 & 0.0 & 0.0 & 5.2 & 0.0 & 4.8 \\
\hline 14 & Humorístico & 0.0 & 0.0 & 0.0 & 6.7 & 0.0 & 1.5 \\
\hline 15 & Propaganda Política & 0.0 & 3.9 & 0.0 & 3.7 & 0.0 & 1.5 \\
\hline 16 & Variedades & 0.0 & 0.0 & 15.0 & 16.2 & 0.5 & 6.4 \\
\hline 17 & Game Show & 0.0 & 0.0 & 0.0 & 10.4 & 0.0 & 2.4 \\
\hline & Total & 100 & 100 & 100 & 100 & 100 & 100 \\
\hline
\end{tabular}

Fonte: Os autores

Realizando uma leitura quantitativa sobre a distribuição dos 17 gêneros transmitidos pelo SBT no Estado de São Paulo, observamos que os telejornais são exibidos, a maioria $(26,1 \%)$ no período da madrugada que corresponde 00h00min até as 05h59min. Aqui, cabe precisar que geralmente os telejornais nesse período são transmitidos a partir das 04h00min. 
Com $20,8 \%$, o gênero informativo é ofertado no primeiro período e com $19,7 \%$ no horário nobre ( $19 \mathrm{~h} 00 \mathrm{~min}$ até às $23 \mathrm{~h} 59 \mathrm{~min}$ ). Notamos nula a produção de programas informativos nos períodos AA (10h00min até às $14 \mathrm{~h} 59 \mathrm{~min})$ e uma reduzida projeção do gênero no período AAA (15h00min até às $18 \mathrm{~h} 59 \mathrm{~min}$ ).

Já os programas de reportagens são centrados com uma porcentagem de $27,9 \%$ no primeiro período de transmissão de programas, que o converte no conteúdo dominante no horário das $06 \mathrm{~h} 00 \mathrm{~min}$ as $09 \mathrm{~h} 59 \mathrm{~min}$. Nota-se uma pequena participação do gênero no horário prime time e uma e restringida presença nos demais períodos da grade de programação.

O gênero entrevista é produzido (3,5\%), exclusivamente, para transmissão no horário da madrugada (AAAAA). Os documentários marcam presença em dois períodos, a saber: com $8,1 \%$ no primeiro período (A) e com $(4,4 \%)$ no período AAA. Os programas de auditórios são transmitidos em três consecutivos períodos, são eles: AA (6,9\%) no período da tarde, AAA com acentuado (14,7\%) e horário nobre $(5,0 \%)$. Os desenhos animados são exibidos massivamente no período AA e mínima presença no primeiro período (1,8\%). A transmissão de novelas segue três períodos consecutivos, iniciando no período AA com uma porcentagem de $13,6 \%$, marcando forte presença no período $A A A$, com expressivo $32,7 \%$ e diminuindo a transmissão do gênero no horário prime time para 5,8\%. Quanto às séries, cabe destacar que é o único gênero transmitido em todos os períodos da grade da programação. Inicia sua projeção com 15,5\% no primeiro período (A), em sequência quadriplica o número de transmissão para $54,8 \%$ no segundo período (AA), reduz para $14,7 \%$ no terceiro período (AAA), segue reduzindo para $9,1 \%$ no horário prime time e aumenta a oferta do gênero para 31,1\% no horário da madrugada. Os telefilmes marcam forte presença no horário da madrugada (AAAAA), com 32,9\% de exibição. Nota-se, também, a presença do gênero no segundo período (AA). Os filmes são transmitidos somente em dois períodos, são eles: horário nobre $(9,5 \%)$ e 3,2\% no horário da madrugada. O gênero musical é ofertado com $2,6 \%$ somente no horário prime time. Os formatos de talk show são transmitidos, exclusivamente, no período AAA $(15,0 \%)$. Já o gênero infantil marca presença $(25,8 \%)$ no período matinal (A) e, particularmente, o mesmo gênero é transmitido no horário nobre (5,2\%). Os programas humorísticos são ofertados unicamente no horário nobre (6,7\%). A propaganda política é centralizada para exibição no segundo período (AA) e no período prime time (AA). O programa de variedades é apresentado em três períodos, a saber: $15 \%$ compõem o período AAA e $16,2 \%$ ofertados no horário prime time e no período da madrugada $(0,5 \%)$. $\mathrm{E}$, por último, o gênero game 
show é apresentado somente no horário nobre (10,4\%) de produção do total da amostra no estado de São Paulo.

Tabela 9. Gênero por período de transmissão do Sistema Brasileiro de Televisão no estado do Rio Grande do Sul

\begin{tabular}{|c|c|c|c|c|c|c|c|}
\hline \multirow{2}{*}{\multicolumn{2}{|c|}{ Gênero }} & \multicolumn{5}{|c|}{ Período de Transmissão } & \multirow[t]{2}{*}{ Total } \\
\hline & & A & AA & AAA & AAAA & AAAAA & \\
\hline 1 & Telejornal & 25.3 & 12.3 & 0.0 & 18.7 & 24.4 & 17.1 \\
\hline 2 & Reportagem & 27.1 & 0.0 & 0.6 & 5.5 & 2.9 & 5.9 \\
\hline 3 & Entrevista & 0.0 & 0.0 & 0.0 & 0.4 & 3.4 & 1.1 \\
\hline 4 & Documentário & 3.4 & 0.0 & 7.2 & 0.0 & 0.6 & 1.8 \\
\hline 5 & Auditório & 0.0 & 5.8 & 15.8 & 4.9 & 0.0 & 4.5 \\
\hline 6 & Desenho Animado & 3.8 & 11.5 & 0.0 & 0.6 & 0.0 & 2.8 \\
\hline 7 & Novela & 0.0 & 6.5 & 39.2 & 5.3 & 0.0 & 8.6 \\
\hline 8 & Séries & 9.2 & 50.9 & 7.5 & 14.2 & 28.6 & 23.6 \\
\hline 9 & Seriado & 4.5 & 8.0 & 0.0 & 0.4 & 33.8 & 12.1 \\
\hline 10 & Filme & 0.0 & 0.0 & 0.0 & 7.9 & 5.0 & 3.2 \\
\hline 11 & Musical & 4.8 & 0.0 & 0.0 & 2.3 & 0.6 & 1.4 \\
\hline 12 & Talk Show & 0.0 & 0.0 & 15.3 & 0.0 & 0.0 & 2.4 \\
\hline 13 & Infantil & 21.9 & 2.0 & 0.0 & 4.9 & 0.0 & 4.5 \\
\hline 14 & Humorístico & 0.0 & 0.0 & 0.0 & 4.5 & 0.0 & 1.0 \\
\hline 15 & Propaganda Política & 0.0 & 2.8 & 0.0 & 2.8 & 0.0 & 1.1 \\
\hline 16 & Variedades & 0.0 & 0.3 & 15.3 & 17.8 & 0.5 & 6.6 \\
\hline & Game Show & 0.0 & 0.0 & 0.0 & 9.8 & 0.0 & 2.2 \\
\hline & Total & 100 & 100 & 100 & 100 & 100 & 100 \\
\hline
\end{tabular}

Fonte: Os autores.

Sobre a transmissão dos 17 gêneros transmitidos na emissora do SBT no Rio Grande do Sul, apresentamos os dados seguintes.

Observa-se no estado do Rio Grande do Sul que os telejornais são em maior volume ofertados no primeiro período $(25,3 \%)$ e no período da madrugada $(24,4 \%)$. Nota-se a ausência de telejornais no período AAA. Um elemento a se destacar é o acréscimo de produção de programas jornalísticos nesse Estado. Os programas de reportagens são ofertados em maior volume $(27,1 \%)$ no primeiro período (A). O gênero também compõe o horário nobre $(5,5 \%)$ e uma reduzida presença nos demais períodos da grade de programação. O programa de entrevista é produzido para transmissão no horário da madrugada $(3,4 \%)$, mas observamos, também, uma tímida presença $\quad(0,4 \%)$ no horário prime time. Os documentários foram exibidos no primeiro período $(A)$ e, em maior volume (7,2\%), no período AAA. Os programas de auditórios são transmitidos em três consecutivos períodos, são eles: AA $(5,8 \%)$, no período da tarde $(15,8 \%)$ e no horário nobre (4,9\%). 
Os desenhos animados são exibidos no primeiro período $(3,8 \%)$, no segundo período (AA) com maior volume de oferta (11,5\%) e observa-se sua presença $(0,6 \%)$ no horário prime time. As transmissões do gênero novelas se distribuem em três períodos contínuos: dá-se início no período AA (6,5\%), salta massivamente para $39,2 \%$ no período AAA e reduz sua exibição no horário nobre (5,3\%).

Da mesma maneira que o SBT-SP, as séries são"programadas" para exibição nos cincos períodos, sendo predominantes no período AA (50,9\%) e no período da madrugada (28,6\%). Outro elemento peculiar é a distribuição dos telefilmes: inicia-se sua exibição no primeiro período (4,5\%), dobra-se a emissão do gênero no segundo período (8,0\%), é ofertado no horário prime time com uma reduzida porcentagem $(0,4 \%)$ e acentua sua transmissão no horário da madrugada $(33,8 \%)$. Os filmes são transmitidos no horário prime time $(7,9 \%)$ e no horário da madrugada (5,0\%). Particularmente, no estado do Rio Grande do Sul, o SBT exibiu o gênero musical em três períodos, a saber: período $A(4,8 \%)$, horário nobre $(2,3 \%)$ e período da madrugada (0,6\%). De igual maneira ao SBT-SP, os programas de Talk Show são transmitidos exclusivamente no período AAA $(15,3 \%)$. O gênero infantil se apresenta massivamente no primeiro período $A$ $(21,9 \%)$, no segundo período reduzido a $2,0 \%$ de exibição e transmitido (4,9\%) no horário prime time. Os programas humorísticos são ofertados, exclusivamente, no horário nobre $(4,5 \%)$.

A propaganda política (de transmissão obrigatória) é exibida no segundo período (AA) e no período prime time. No que tange a programas de variedades, encontramos a seguinte distribuição: período $A(0,3 \%)$, período $A A,(15,3 \%)$, período prime time $(17,8 \%)$ e período da madrugada $(0,5 \%)$. A oferta de programa de game show é exclusivamente exibida no horário nobre $(9,8 \%)$, do total da amostra da emissora SBT no Estado do Rio Grande do Sul. 
Tabela 10. Gênero por período de transmissão TV Aratu no estado da Bahia.

\begin{tabular}{|c|c|c|c|c|c|c|c|}
\hline \multicolumn{2}{|c|}{ Gênero } & \multicolumn{5}{|c|}{ Período de Transmissão } & \multirow[t]{2}{*}{ Tota } \\
\hline & & A & AA & AAA & AAAA & AAAAA & \\
\hline 1 & Telejornal & 19.5 & 9.4 & 13.8 & 24.9 & 12.9 & 15.5 \\
\hline 2 & Reportagem & 20.3 & 23.3 & 10.3 & 10.8 & 2.7 & 12.9 \\
\hline 3 & Entrevista & 0.0 & 0.0 & 0.0 & 0.2 & 7.3 & 2.0 \\
\hline 4 & Documentário & 3.0 & 0.0 & 5.4 & 1.8 & 0.8 & 2.0 \\
\hline 5 & Auditório & 0.0 & 1.5 & 15.9 & 5.1 & 0.0 & 3.7 \\
\hline 6 & Desenho Animado & 1.4 & 8.5 & 0.0 & 0.7 & 0.0 & 2.2 \\
\hline 7 & Novela & 0.0 & 2.8 & 28.5 & 3.8 & 0.0 & 5.9 \\
\hline 8 & Séries & 7.2 & 2.3 & 3.6 & 0.2 & 35.5 & 12.2 \\
\hline 9 & Seriado & 0.0 & 0.7 & 0.0 & 0.7 & 20.8 & 5.7 \\
\hline 10 & Filme & 0.0 & 0.0 & 0.0 & 3.5 & 5.2 & 2.0 \\
\hline 11 & Programa Esportivo & 0.5 & 7.1 & 0.0 & 0.0 & 0.0 & 1.6 \\
\hline 12 & Musical & 0.0 & 3.3 & 0.0 & 2.4 & 0.1 & 1.1 \\
\hline 13 & Talk Show & 0.5 & 0.0 & 10.7 & 0.0 & 4.6 & 3.1 \\
\hline 14 & Reality Show & 0.0 & 2.8 & 0.0 & 0.2 & 0.0 & 0.6 \\
\hline 15 & Infantil & 5.9 & 13.5 & 0.0 & 6.6 & 0.0 & 5.0 \\
\hline 16 & Humorístico & 0.0 & 0.0 & 0.0 & 4.6 & 0.0 & 0.7 \\
\hline 17 & Culto Religioso & 27.8 & 0.0 & 0.2 & 0.0 & 10.2 & 8.2 \\
\hline 18 & Propaganda Política & 0.0 & 2.3 & 0.0 & 2.6 & 0.0 & 0.9 \\
\hline 19 & Variedades & 5.6 & 19.9 & 10.5 & 23.0 & 0.6 & 10.8 \\
\hline 20 & Game Show & 1.6 & 2.5 & 1.3 & 8.8 & 0.0 & 2.4 \\
\hline 21 & Quiz Show & 0.0 & 0.2 & 0.0 & 0.0 & 0.0 & 0.0 \\
\hline 22 & Telecompra & 6.6 & 0.2 & 0.0 & 0.0 & 0.0 & 1.3 \\
\hline & Total & 100 & 100 & 100 & 100 & 100 & 100 \\
\hline
\end{tabular}

Fonte: Os autores.

O tratamento estatístico dos dados da emissora afiliada ao SBT, TV Aratu no estado da Bahia, apresenta o seguinte panorama dos 22 gêneros encontrados nessa emissora:

Destaca-se na TV Aratu a produção do gênero jornalístico nos cinco períodos classificados por nossa investigação, com destaque para o período $\mathrm{A}$ $(19,5 \%)$ e no período prime time (24,9\%). Observa-se que, de similar maneira, o gênero reportagem é distribuído também nos cinco períodos, dobrando a porcentagem de programas produzidos pela TV Aratu. Adverte-se a emissão desse gênero no primeiro período $A(20,35 \%)$ e no período AA (23,3\%). Os programas de entrevista são exibidos no período da madrugada $(7,3 \%)$ e com participação reduzida no horário nobre $(0,2 \%)$. Os documentários foram exibidos no período $A(3,0 \%)$, no período AAA $(5,4 \%)$, no horário nobre $(1,8 \%)$ e no período AAAAA $(0,8 \%)$. Os programas de auditórios são transmitidos em 
três consecutivos períodos, são eles: AA (1,5\%), AAA (15,9\%) e no horário nobre $(5,1 \%)$.

Uma informação a se sobressair é a redução de oferta da TV Aratu dos desenhos animados comparada aos demais Estados analisados. Nota-se a exibição no período $A(1,4 \%)$, no período $A A(8,5 \%)$ e no horário nobre $(0,7 \%)$. A oferta do gênero novelas inicia-se no período $A A(2,8 \%)$, aumenta seu volume no período AAA $(28,5 \%)$ e é reduzida sua projeção no horário nobre (3,8\%). Dáse inicio no período AA (6,5\%), salta massivamente para $39,2 \%$ no período AAA e reduz sua exibição no horário nobre (5,3\%).

Particularmente as séries são significativamente reduzidas pela TV Aratu no Estado da Bahia nos quatro primeiros períodos estabelecidos, sendo exibidos majoritariamente $(35,5 \%)$ no período AAAAA. Igualmente, os telefilmes são reduzidos, sendo programados para exibição no período $A A(0,7 \%)$, mantém a mesma porcentagem de distribuição do gênero no horário prime time $(0,7 \%)$ e é ofertado em maior volume no horário AAAAA $(20,1 \%)$. Já os filmes são transmitidos no horário prime time $(3,5 \%)$ e no horário da madrugada $(5,2 \%)$, gênero também com redução de oferta.

Constata-se a presença de programas esportivos exibidos pela TV Aratu, ofertado no período $A(0,5 \%)$ e no período $A A(7,1 \%)$. O gênero musical é transmitido no período AA (3,3\%) e no horário prime time $(2,4 \%)$. Verifica-se que os programas de Talk Show são exibidos em três períodos, são eles: período A $(0,5 \%)$, período AAA $(10,7 \%)$ e no período AAAAA (4,6\%). Observamos que na afiliada TV Aratu se produz programas de Reality Show exibidos no período AA $(2,8 \%)$ e período AAAA $(0,2 \%)$.

Especialmente o gênero infantil é transmitido em três períodos, a saber: inicia sua projeção no primeiro período $A(5,9 \%)$, período AA $(13,5 \%)$ e período AAAAA (6,6\%). Os programas humorísticos são exibidos unicamente no período AAAA (4,6\%). Faz-se necessário advertir a presença significativa de programas religiosos na afiliada TV Aratu. Esse gênero lidera o período A (27,8\%), do total de todos os programas transmitidos em referido período. Destaca-se, também, sua exibição no período AAAAA (10,2\%). Como já mencionado, os programas políticos são transmitidos nos períodos AA e no período AAAA.

Ressaltamos maior oferta dos programas de variedades e participação em todos os períodos. Destacamos esse gênero nos períodos AA (19,9\%) e no período AAAA (23,0\%). Particularmente na TV Aratu a oferta de programa de Game show é distribuída em quatros períodos, com maior participação, assim como nos demais Estados no período AAAA (8,8\%). Dois novos gêneros são encontrados na TV Aratu, são eles: Quiz Show (0,2\%) exibido somente no período AA e o gênero Tele compra nos períodos $A(6,6 \%)$ e $A A(0,2 \%)$. 


\section{Conclusões}

Os dados quantitativos, objeto norteador do nosso estudo, revelam que a cadeia de produção e programação do SBT-SP; SBT-RGS e afiliada TV Aratu apresentam uma contraposição na formação da grade televisiva no que diz respeito a números de programas e gêneros ofertados nos períodos por ambas emissoras.

Faz-se necessário destacar a ausência absoluta de programas religiosos em dois Estados: SBT-SP e SBT-RGS, e uma inversão bastante significativa no estado da Bahia.

Nesse contexto, o tratamento estatístico aplicado nos permite revelar que a estrutura que compõe a grade televisiva do SBT-SP, SPT-RGS eTV Aratu declara um total descumprimento do artigo 221 da Constituição Federal (1988), com inexistente produção de conteúdos educativos, artísticos, culturais, massiva transmissão de programas de entretenimento face ao número de produção de programas informativos.

Comojá anunciamos, acresce a esses fatores trazidos, gêneros classificados pela própria emissora que se descaracterizam por agregar outras atrações. sobretudo as publicidades.

Nesse âmbito, os programas de telejornais são os que mais perdem seu caráter informativo, além de apresentar uma carga de subjetividade no discurso de seus apresentadores. Neste sentido, estudo realizado pela Agência de Notícias dos Direitos da Infância (ANDI) apontou que os programas transmitidos nas dez principais capitais brasileiras empregados como noticiosos incitam "a sensação de impunidade, o descrédito nas instituições responsáveis pela administração da justiça e a crença no caminho da violência, da intolerância, do arbítrio e do crime" (ANDI, 2015, p. 67).

Cabe precisar que, ao realizar a leitura textual dos programas ofertados pela emissora examinada, observou-se diversos frames durante alguns programas transmitidos de produtos da marca Jequiti Cosméticos, empresa do grupo Silvio Santos.

Dados esses indicativos, urgem investigações que realizem leituras dos elementos que constituem as obras audiovisuais ofertadas pela indústria televisiva, atrelados a pesquisas empíricas sobre a produção, distribuição e transmissão dessas obras para constatar as articulações aplicadas nos conteúdos e os efeitos que causam na população brasileira. A agenda de discussão deve ser aberta, estimulando a construção do corpus teórico e metodológico, fomentando a construção de indicadores sobre os conteúdos e seu planejamento, contrastando estudos subsequentes com séries temporais 
que nos permitam recomendar aos produtores, programadores e legisladores, medidas idôneas para uma dieta audiovisual saudável no mercado televisivo nacional.

\section{REFERÊNCIAS}

BAKHTIN, Mikhail. Estética da criação verbal. São Paulo: Martins Fontes, 2006.

BARDIN, Laurence. Análisis de contenido. Madrid: Akal, 1997.

Análise de conteúdo. São Paulo: Edições 70, 2011.

BIONDI, Antonio; CHARÃO, Cristina. Terra de gigantes. Revista ADUSP, p. 6-25, jan. 2008.

BOLAÑO, César. A economia política da televisão brasileira. Intercom - Revista Brasileira de Ciências da Comunicação.v. 22, n. 2, 1999.

Mercado brasileiro de televisão. São Paulo: PUC-SP, 2004.

BRASIL. Constituição (1988). Emendas de n 1 a 15. Brasília: STF, 1996.

BRASÍLIA: ANDI; Secretaria Nacional da Justiça. Classificação indicativa: construindo a cidadania na tela da tevê, 2006.

BRITTOS, Valério Cruz. História, economia política e tendência da TV Brasileira. Comunicação e cultura. Caxias do Sul, v. 1, n. 1, p. 19-42, 2002.

. Globo, transnacionalização e capitalismo. In: ;BOLAÑO, César Ricardo (Orgs.) Rede Globo: 40 anos de poder e hegemonia 2. ed. São Paulo, 2005. p. 131-145, 2005.

CAPPARELLI, Sérgio. A periodização nos estudos de televisão. Intexto, v. 1, p.1-16, 2008.

CASETTI, Francesco; DI CHIO Frederico. Análisis de la televisión: instrumentos, métodos y prácticas de investigación. Barcelona: Paidós, 1999.

CONDORI, J. A. S. Análisis de datos clínicos y epidemiológicos. 2011. Disponível em: $<$ http://www.bioestadistico.com>. Acesso em: 5 out. 2001.

DUARTE, Elizabeth Bastos. Televisão: ensaios metodológicos. Editora Sulina, 2004.

FECHINE, Yvana. Núcleo Guel Arraes: Formação, Influências e contribuições para uma TV de qualidade no Brasil. In: FIGUERÔA, Alexandre (Org.). Guel Arraes: um inventor no audiovisual no Brasil. Recife: Cepe, 2008.

FILHO, João Freire. A TV em transição: tendências de programação no Brasil e no 
mundo. Porto Alegre: Sulina, 2009.

GALHARDI, Cláudia Pereira; ORTEGA, Felix. Fluxo da Programação televisiva aberta no Brasil: Uma nova proposta metodológica e caso prático no Estado de São Paulo. In: XXXVI Congresso Brasileiro de Ciências da Comunicação INTERCOM, 2013, Manaus. $36^{\circ}$ Congresso Brasileiro de Ciências da Comunicação. Intercom, Manaus, v. 1, 2013.

GALHARDI, Cláudia Pereira. Investigación de los flujos en Brasil: análisis de la parrilla de programación de la televisión en los Estados de São Paulo, Rio Grande do Sul y Salvador de Bahía, 2014. Tese (Doutorado em Comunicação Audiovisual) - Departamento de Sociologia e Comunicação, Salamanca, Universidade de Salamanca - Espanha, 2014.

GALHARDI, Cláudia Pereira; ORTEGA, Felix; IGARTUA, Juan José. Investigación de los flujos comunicacionales en Brasil: panorama de la parrilla de televisión abierta comercial en el Estado de São Paulo. Revista Intercom, v. 38, n.1, p. 255-272, jan/jun. 2015.

GARZA, Javier Martínez. La oferta de televisión en América Latina: hacia un análisis de flujos. ZER. México, n. 19, p. 145-27, 2005.

GARZA, Francisco Javier Martínez; LOZANO, José Carlos. Flujos televisivos y cinematográficos en México. Comunicación y sociedad, n. 3, p. 47-66, 2005.

IGARTUA, Juan José. Métodos cuantitativos de investigación en Comunicación. Barcelona: Bosch, 2006.

JAMBEIRO, Othon; BRITTOS, Valério Cruz; SIMIS, Anita. O capitalismo internacional e as novas configurações da regulação da informação e da comunicação. Revista ALAIC, n. 6, p. 42-59, 2011.

KRIPPENDORFF, Klaus. Content Analysis: an introduction to its methodology. Los Ángeles: Sage, 2013.

. Metodología de análisis de Contenido: Teoría y práctica. Barcelona: Paidós, 1990.

LOZANO, José Carlos. Conglomerados de mídia e fluxos audiovisuais na América Latina. In: Comunicação, Mídia e Consumo. São Paulo, v. 2, n. 5, p. 91-121, 2005.

MALCHER, Maria Ataíde. Gênero ficcional televisivo: Instância mediadora da Comunicação massiva. In: XXIV Congresso Brasileiro de Ciência da Comunicação: A mídia impressa, o livro e o desafio das novas tecnologias, Campo Grande. Anais eletrônicos... Campo Grande. Disponível em: < htpp:/ www.intercom.org.br/papers/nacionais/2001/papers/NP14MALCHER.PDF>. Acesso em: 15 abr. 2013. 
MAZZIOTTI, Nora. Tendencias en la circulación de programas televisivos en el Mercosur. Revista Famecos, Porto Alegre, n. 14, p. 36-44, 2001.

MELO, José Marques de. Para uma leitura crítica da Comunicação. São Paulo: Paulinas, 1985.

MIRA, Maria Celeste. Circo eletrônico: Silvio Santos e o SBT. São Paulo: Edições Loyola, 1994.

NORDENSTRENG, Kaarle; VARIS, Tapio. ¿Circula la televisión en un solo sentido? Examen y análisis de la circulación de los programas de televisión en el Mercosur. Paris: Editoral da Unesco, 1976. Disponível em: < http://unesdoc.unesco.org/ images/0013/0pdf01342/134279so > Acesso em: 15 mar. 2011.

ORTEGA, Félix; GALHARDI, Cláudia. Propuesta metodológica para el análisis de contenido de la parrilla de televisión en Brasil: Análisis de un caso práctico en los Estados de São Paulo, Rio Grande do Sul, Estado da Bahía. In: Congreso Nacional sobre Metodología de la Investigación en Comunicación y del Simposio Internacional sobre Política Científica en Comunicación, Segovia. Anais electrônicos... Segovia. Disponível em: <htpp://dialnet.unirioja.es/servlet/ articulo?Codigo=4228799 > . Acesso em: 18 jun. 2013.

ORTIZ, Renato. A moderna tradição Brasileira: cultura brasileira e indústria cultural. São Paulo: Brasiliense, 2006.

REIMÃO, Sandra. Em Instantes: um estudo sobre programas da TV brasileira (19652000). São Paulo: Universidade Metodista de São Paulo, 2006.

REVISTA VEJA. Silvio ao Vivo. Disponível em: <http://veja.abril.com.br/acervodigital/ home.aspx>. Acesso em: 10 mar. 2015.

RONDELLI, Elizabeth. Televisão aberta e por assinatura: consumo cultural e política de programação. Revista Lugar Comum, n. 5-6, p. 33-58, 1998.

SACRAMENTO, IGOR. Os estudos de televisão no Brasil. Panorama da comunicação e das telecomunicações no Brasil. Brasília: Ipea, 2013.

SILVA, Arlindo. A fantástica história de Silvio Santos. São Paulo: Editora do Brasil, 2000.

SOUZA, José Carlos Aronchi de. Gêneros e formatos na televisão brasileira. São Paulo: Summus, 2004.

SOUZA, Silvia Maria. Silvio Santos vem aí: programas de auditório do SBT numa perspectiva semiótica, 2009. Tese (Doutorado em Estudos Linguísticos). Rio de Janeiro: Universidade Federal Fluminense, 2009.

TONDATO, Márcia Perecin. Negociação de sentido: recepção da programação de TV aberta, 2004. Tese (Doutorado em Comunicação) - Escola de Comunicações e 
Artes, São Paulo, Universidade de São Paulo (USP), 2004.

WOLTON, Dominique. Elogio del gran público. Barcelona: Gedisa,1998.

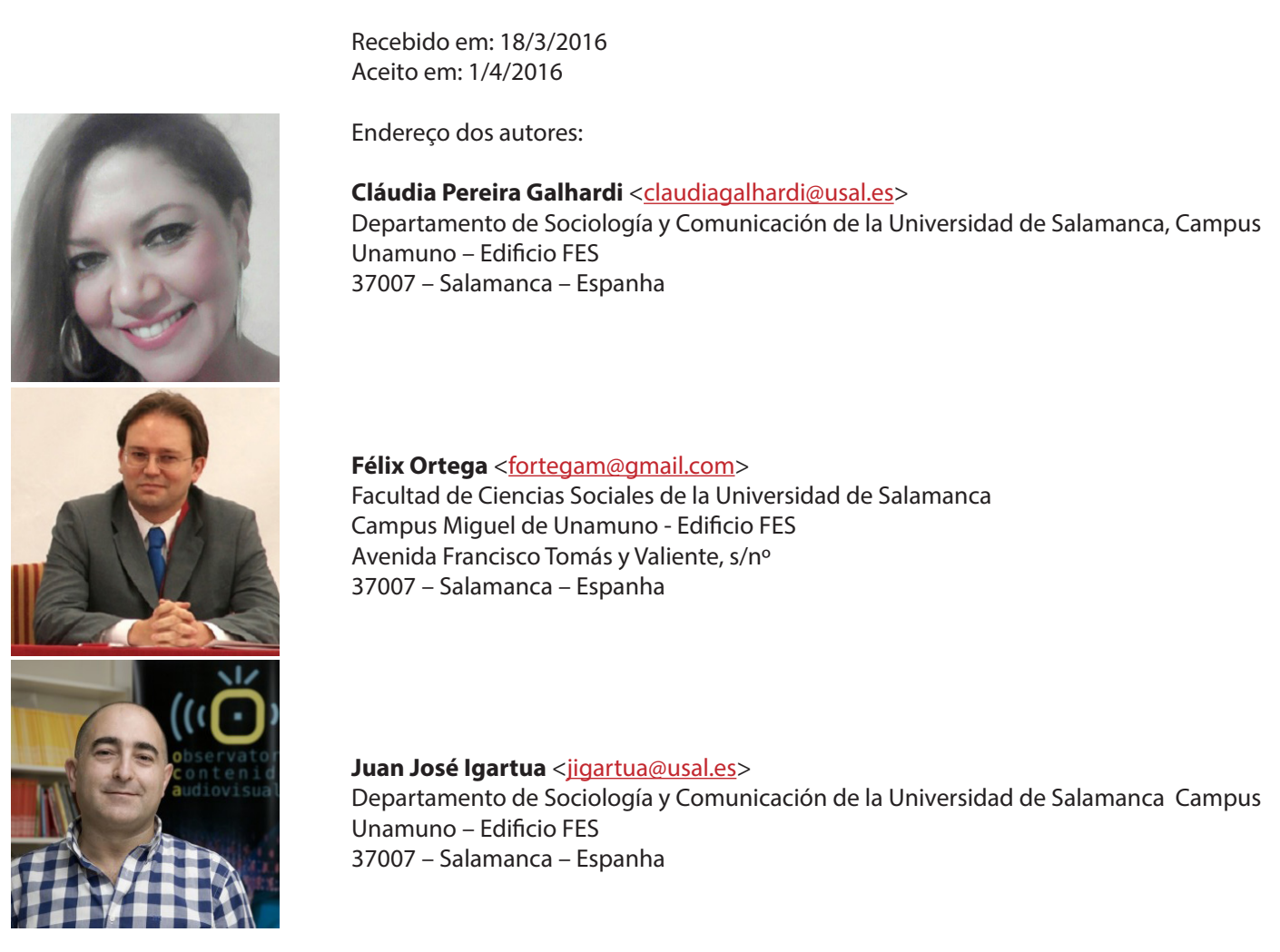

